\title{
Diferenciação Sócioespacial e Percepções da Espacialidade de Maputo - Cidade
}

\author{
Socio-Spatial Differentiation and Perceptions of Maputo-City Spatiality \\ Diferenciación Socioespacial y Percepciones de la Espacialidad de la Ciudad de \\ Maputo
}

Luiz Adriano Guevane ${ }^{1}$

RESUMO: Refletir em torno da percepção da imagem espacial de cidade, no caso vertente de MaputoCidade, constituiu o objetivo central deste artigo. Para detectar as referidas percepções, à luz da geografia da percepção, metodologicamente, sem deixar de lado as vivências e experiências do autor sobre o assunto em causa, usou-se, por um lado, a técnica de análise de textos e, por outro, administrou-se um inquérito. O mote orientador do artigo foi a busca de razões para o fato de a "imagem verticalizada" prevalecer sobre a "imagem horizontalizada" na determinação do entendimento de cidade. A partir da análise de textos concluímos que a percepção de diferenciação espacial funda-se no caráter alógeno e na rápida urbanização da cidade de Maputo. Este aspecto é encontrado na pesquisa de campo, por meio da protuberância da "imagem verticalizada" que gera uma diversidade de limites percepcionados e condiciona as percepções relativas ao conteúdo do conceito cidade.

PALAVRAS-CHAVE: Geografia da percepção. Cidade. Imagem verticalizada. Imagem horizontalizada. Limites percepcionados.

ABSTRACT: The main objective of this article is the reflection around the perception of the spatial image of Maputo city. To detect these perceptions, in the wake of the geography of perception, without neglecting the author's experiences on the subject in question, the text analysis technique was used and a survey was administered. The article seeks the reasons why the "vertical image" prevails over the "horizontal image" in determining the understanding of the city. From the analysis of texts, we conclude that the perception of spatial differentiation is based on the allogeneic character and rapid urbanization of the city of Maputo. This aspect is found in field research where the protuberance of the "vertical image" generates a diversity of perceived territorial boundaries, conditioning the content of the city concept.

KEYWORDS: Geography of perception. City. Verticalized image. Horizontalized image. Percepted limits.

RESUMEN: El objetivo principal de este artículo es reflexionar sobre la percepción de la imagen espacial de la ciudad de Maputo. Para detectar estas percepciones, en función de la geografía de la percepción y las experiencias del autor sobre el tema, se utilizó la técnica de análisis de texto y se

\footnotetext{
${ }^{1}$ Universidade Pedagógica de Maputo, Departamento de Geografia, Campus de Lhanguene, Caixa Postal 4040, Maputo, Moçambique, Av. de Moçambique, Km 1,5. luisguevane@gmail.com.
} 
administró una encuesta. El artículo busca las razones por las cuales la "imagen vertical" prevalece sobre la "imagen horizontal" para determinar la comprensión de la ciudad. Del análisis de textos concluimos que la percepción de diferenciación espacial se basa en el carácter alogénico y la rápida urbanización de la ciudad de Maputo. Este aspecto se basa en la investigación de campo donde la protuberancia de la "imagen vertical" genera una diversidad de límites territoriales percibidos, condicionando el contenido del concepto de ciudad.

PALABRAS-CLAVE: Geografía de la percepción. Ciudad. Imagen vertical. Imagen horizontal. Límites percibidos.

\section{INTRODUÇÃO}

A área central de Maputo-Cidade tem sido habitualmente assumida como sendo, de fato, a cidade, embora esta, administrativamente, corresponda a um espaço mais amplo que abarca os seus vários distritos urbanos. No período colonial a cidade podia ser identificada a partir das construções em altura. Os subúrbios, em seu redor, possuíam uma identidade que se pretendia de curto prazo, fundada numa tipologia habitacional de sentido provisório dada a expansão da própria cidade; daí que as construções utilizassem um tipo de material facilmente removível.

A "cidade de cimento" constituía a ideia de cidade pelas construções em altura e pela importância política, económica e social que possuía. Podia-se sair da cidade para o subúrbio ou vice-versa. Após a independência de Moçambique foram herdadas estas características da morfologia urbana do período colonial cuja designação mais representativa era (e continua a ser pelo menos simbolicamente) a chamada "cidade de cimento" e a "cidade de caniço". O novo elemento foi a rápida expansão da urbanização e a ampliação político-administrativa do território da cidade, ação que incluiu a periferia. Neste sentido, a imagem percepcionada (de cidade) não foi coincidente com a agregação feita em termos político-administrativos. Ou seja, os citadinos continuaram a referir, por exemplo, que estão a caminho da cidade quando, na prática, ou seja, na acepção político-administrativa, já se encontram nela (estando em um dos bairros da cidade). Que imagem mental de cidade constroem ao ponto de considerarem somente a área central e seus espaços próximos, mais imediatos, como cidade? Ao relacionarem-se com o meio em seu redor como percebem os limites e os conteúdos que perfazem a cidade?

Esta pesquisa objetivou a problemática da percepção do espaço com o foco dirigido para a capital da República de Moçambique, Maputo Cidade (Longitude: $32^{\circ} 25^{\prime}$ a $32^{\circ} 40^{\prime}$; Latitude: $25^{\circ} 50^{\prime}$ a $26^{\circ}$ 05', Sul; Altitude: 0 a 60 metros), trazendo à tona o sentido de cidade em interface com os respetivos limites. Desse modo, fundamentado na geografia da 
percepção, que usa entre os seus métodos os mapas cognitivos ou mentais, as entrevistas, a análise de textos bem como o inquérito, optamos por estes dois últimos pela adequação e relevância relativamente ao alcance dos objetivos da presente pesquisa. Assim, a mesma teve por base i) a administração de um inquérito a um grupo de 34 indivíduos (presentes no momento da coleta de informação), ii) as experiências e vivências do autor, e, iii) a análise de textos como método próprio da geografia da percepção, fazendo o estudo do espaço através de percepções. Na técnica de análise de textos foram usados estudos de conteúdo urbanogeográfico de autores como Araújo (2002, 2003, 2005), Viana (2012), e Viana, Sanz e Natálio (2013), entre outros.

O artigo encontra-se dividido em três partes. A primeira versa sobre a percepção do espaço, onde são abordados os conceitos de cidade e urbano como espaços percebidos. A segunda parte trata das percepções sobre as imagens horizontalizada e verticalizada da cidade de Maputo, tendo como foco a perspectiva histórica e a análise de textos como técnica geográfica para estudar o espaço. Assim, revisitou-se o conceito de urbano e de cidade, olhando para a realidade em causa e para os impactos das migrações e da reclassificação administrativa (como influenciadores da percepção). Finalmente, a terceira parte resulta de uma pesquisa de campo baseada em duas questões: uma sobre os limites percepcionados e, outra, sobre o conteúdo da cidade.

\section{A PERCEPÇÃO DO ESPAÇO E OS CONCEITOS DE CIDADE E URBANO}

O espaço percebido ou subjetivo constitui objeto de estudo da geografia da percepção, como notou Muñoz (2010). Olhando concretamente para a geografía, referiu que "[...] el espacio geográfico es tal si lo es para el/los sujetos; al mismo tiempo el sujeto en Geografía lo es para un espacio" (MUÑOZ, 2010, p. 140).

A percepção, pela carga subjetiva que possui, constitui motivo de reflexões no sentido de se procurar facilitar a sua descrição. Segundo Gava (2015), é uma ação, daí que envolva, por inteiro, o corpo da pessoa, incluindo todos os seus sentidos; é uma atividade consciente. Entre esses sentidos Kanashiro (2003) olha para a visão como o mais importante, por considera-lo dominante nos seres humanos, proporcionando, por isso, muito mais informação que os restantes sentidos. É ainda Kanashiro (2003, p. 157), citando Rapoport, Tuan e Kohlsdorf, quem acrescenta que estudos feitos por pesquisadores apontam que, "através do ambiente visual, são construídas as relações de espaço, distância, textura, luz, cor, forma, contraste e todas as demais formas de apreensão do espaço arquitetônico".

Segundo Gava (2015, p. 131-132), "Há uma série de atividades que o sujeito percipiente desenvolve para que a percepção seja bem-sucedida, não há mera passividade frente ao estímulo exterior". Ou seja, como Smith (2014) observou, a percepção expressa a relação 
entre a "pessoa que percebe" e o "objeto ou evento no mundo". É assim que o homem precisa ler o ambiente em que está inserido, focalizando referências e orientação, de modo a construir uma percepção sobre o espaço. A referida leitura, quando fácil, corresponderá, então, a um ambiente com boa legibilidade, ou seja, diferenciável, singular, com apreciável grau da relação habitante-cidade, que é um fator importante no uso desses espaços (SCOCUGLIA; CHAVES; LINS, 2006).

Segundo Kanashiro (2003, p. 156), baseado no modelo perceptivo adaptado de Rapoport, se a partir de estímulos exteriores podemos perceber o meio ambiente, por outro lado, os filtros, variando em função das culturas, podem proporcionar "diferentes imagens do mundo 'real'". Os filtros, ao variarem culturalmente, conduzem a uma imagem do mundo percebido como um todo coerente. Paralelamente, a interação das pessoas para com o meio ambiente também dependeria de certos significados individuais construídos. Desse modo, as percepções de cidade e de urbano, por exemplo, no sentido dos limites e dos conteúdos da sua grandeza ou da sua organização espacial, derivariam da vivência de cada indivíduo e dos respectivos filtros culturais.

Três definições de "cidade" são apresentadas por Hassenpflug (2007): uma que considera a cidade como criação da filosofia da história, outra de âmbito sociológico e, uma última, básica como as duas primeiras, ainda segundo o mesmo autor, que põe o foco na centralidade cultural. Na primeira, a cidade e a sua história são produto e produtor da civilização. Olha-se para a cidade como força espacial impulsionadora do avanço da sociedade e sua libertação das matrizes tradicionais, ou seja, a cidade é uma "máquina civilizadora". Na segunda, a cidade é conceituada como um agregado de diversidade e diferença; são tomadas em consideração características como o tamanho, a permanência, a densidade e a heterogeneidade. Por último, como lugar de centralidade cultural, a cidade pode ser definida pela existência de um ou mais centros. Servem de exemplos a hierarquia de centro principal, os subcentros e os centros de vizinhança, muito importante(s) no provimento da forma e coerência urbanas, na sua distinção e legibilidade. O maior significado simbólico da cidade está no centro urbano. Aqui a acessibilidade é maior e o solo mais escasso, tornando o "centro" o espaço mais caro da cidade.

O conceito de cidade e urbano, de acordo com Lencione (2008), varia conforme as referências teóricas. Ainda segundo a referida autora, "[...] a idéia de cidade é clara para todos, diferentemente da idéia de urbano. No entanto, o conceito de cidade é obscuro" (LENCIONE, 2008, p. 114). Santos (1959, p. 7) reconheceu ser muito antigo o problema de defini-la corretamente, mas que o ponto de vista do geógrafo, diferentemente dos sociólogos e economistas, é que a cidade constitui uma "[...] forma particular de organização do espaço, uma paisagem e, por outro lado, preside às relações de um espaço maior", em seu redor, sua zona de influência. 
Alguns dos vários autores referidos por Vasconcelos (2006), sobretudo geógrafos, na definição de cidade e urbano são, por exemplo, i) Pierre George, segundo o qual a cidade é fato histórico e também geográfico, pois a sua forma resulta do seu passado e presente, e o seu conteúdo humano e atividade de seus habitantes configurariam o signo do presente; ii) David Harvey, que olha para a cidade como um sistema dinâmico-complexo onde permanecem em interação a forma espacial imbricada com o processo social; do ponto de vista marxista a cidade seria o espaço de tradições acumuladas ou berço de um provável modo de produção; e, iii) Milton Santos, que observa a cidade como algo particular, concreto e interno e o urbano como algo frequentemente abstrato, geral e externo. Kanashiro (2003, p. 159) olha para o senso de lugar e para as relações de percepção do homem com o seu meio através dos sentidos como os aspetos que "[...] delineiam a riqueza de sensações nas cidades. Porém, estas não se fazem de maneira universal, podendo os sentidos serem variáveis entre grupos, cultura, épocas e o meio circundante".

Para Lencione (2008, p. 116), excluindo a atividade agrícola e o tamanho da população, o conceito de cidade inclui as ideias de "[...] aglomerado, sedentarismo, mercado e administração pública, que parecem constituir referências importantes na conceituação de cidade". Lencione (2008), parafraseando Pereira, considera que as dificuldades na compreensão de cidade decorrem do enfoque a-histórico e que a cidade depende de formas políticas e sociais, sendo estes produtos de determinações sociais; formas estas que constituem forças caracterizadoras e individualizadoras.

Olhando concretamente para o conceito de urbano, Vasconcelos (2006) recorre a alguns autores como, por exemplo, i) Louis Wirth, que associa o urbano ao modo de vida, extrapolando o conceito de cidade; ii) Henri Lefebvre), que comunga o urbano com a realidade social feita de relações a conceber pelo pensamento; toma o urbano com uma base, uma morfologia, que se constitui como ponto de encontro; um espaço tendente à centralidade e a policentralidade, e que devido a relativa independência entre as formas e os conteúdos não é tido como um sistema; e, iii) Milton Santos, que, em oposição à cidade, considera o urbano como o espaço do abstrato, do geral, do externo.

Para Araújo (2012) a cidade e o urbano não passam de "formas sociais". No campo da Geografia, ainda segundo o mesmo, tem-se pensado de forma pragmática sobre as formas olhando para a questão da materialidade, no sentido de formas-objeto ou formas-conteúdo; no entanto, encontra em Léfèbvre que "[...] as formas são expressões das estruturas, logo, há formas materiais (prático-sensíveis) como a cidade, mas também formas não-materiais, porém concretas, como as formas lógicas presentes nas relações contratuais" (ARAÚJO, 2012, p. 141).

Neste sentido, a percepção dos limites e da grandeza de uma organização espacial, como a cidade e o urbano, de acordo com os estímulos exteriores e em função dos filtros 
culturais, levam-nos à apreensão de um todo coerente, podendo este ser socialmente diversificado em razão da complexidade do mesmo. Um prédio remete-nos a um determinado tipo de complexidade e compreensão diferentemente do que é uma cidade ou o urbano (ainda que possa ser encontrado nestes dois espaços).

\title{
PERCEPÇÕES SOBRE AS IMAGENS HORIZONTALIZADA E VERTICALIZADA DA CIDADE DE MAPUTO
}

Os aspectos formais que dão conteúdo ao conceito de cidade diferem entre os órgãos de gestão urbana e os munícipes. Enquanto que, por um lado, para os primeiros a questão jurídico-administrativa, no sentido de área territorial sob sua alçada, é fundamental para o exercício legal de suas atividades cotidianas, por outro, para os munícipes, a questão da percepção dos elementos que compõem a cidade e a consciência sobre os mesmos extravasa os aspectos formais. O filtro cultural de cada indivíduo entra no jogo de determinação do conjunto de elementos que no seu imaginário constitui a cidade. Ainda assim, sem fugir às regras e aos padrões dos diferentes espaços, é importante considerar a existência da percepção como resultado de um filtro coletivo nesse sentido, pois os valores simbólicos são partilhados e reforçam as delimitações e os elementos que constituem aquilo que no imaginário das redes de relacionamento se vai considerando conteúdo de cidade.

Como Malanski (2014) referiu, por meio dos cinco sentidos e da mente, as pessoas percebem o espaço em que se encontram e interagem com ele, tornando-se conscientes do mesmo. Sobre este aspecto encontramos em Araújo (2005, p. 93) o seguinte:

\begin{abstract}
A simples observação visual, quando se caminha da periferia para o centro urbano, seja na Matola ou em Maputo, transmite a percepção de se estar a passar por diferentes paisagens urbanas, progredindo duma de ocupação pouco densa, não ordenada, com determinado tipo de material de construção e com uma vida social que transmite determinados valores e comportamentos, até uma outra onde a ocupação do solo é total, o predomínio do betão é a marca fundamental, o ordenamento está presente e a vida apresenta outros ritmos, atitudes e comportamentos.
\end{abstract}

Este retrato de Araújo (2005) sobre a percepção do espaço urbano põe em evidência a questão da legibilidade. Ou seja, apresenta duas formas "facilmente diferenciáveis" de organização espacial e até social. Ele vai elencando a "não ordem" e o "ordenamento", a densidade, os materiais de construção usados, entre outros, conduzindo-nos às diferenças existentes e, implicitamente, aos limites e diferentes grandezas decorrentes dessas realidades. As "diferentes paisagens urbanas" por que se passa levam a uma paisagem também diferente que é a área central, que é o espaço onde a verticalização se impõe como característica dominante. A imagem de cidade parece ser tudo menos um espaço precário. A 
partir de práticas cotidianas, por meio da mobilidade urbana, a consciência que se ganha sobre o espaço urbano, no caso concreto de Maputo-Cidade (figura 1), é de uma periferia com uma imagem marcadamente horizontal, e, pelo contrário, as áreas centrais, com o espaço dominado pela imagem verticalizada, resultando assim em maior legibilidade. Como indicaram os estudos de Viana (2012), a forma urbana de Maputo-Cidade compõe-se de contextos morfológicos reveladores de contrastes onde coexistem processos formais e informais de urbanização, sintetiza regras e padrões quer da "cidade de cimento", espaço de "predomínio do betão", quer do espaço da "cidade de caniço", que nas últimas duas décadas foi abandonando de forma claramente visível em favor do bloco e cimento como resultado do significativo processo que Viana (2012) designou por "cimentalização" da "cidade de caniço".

Figura 1 - Localização da cidade de Maputo

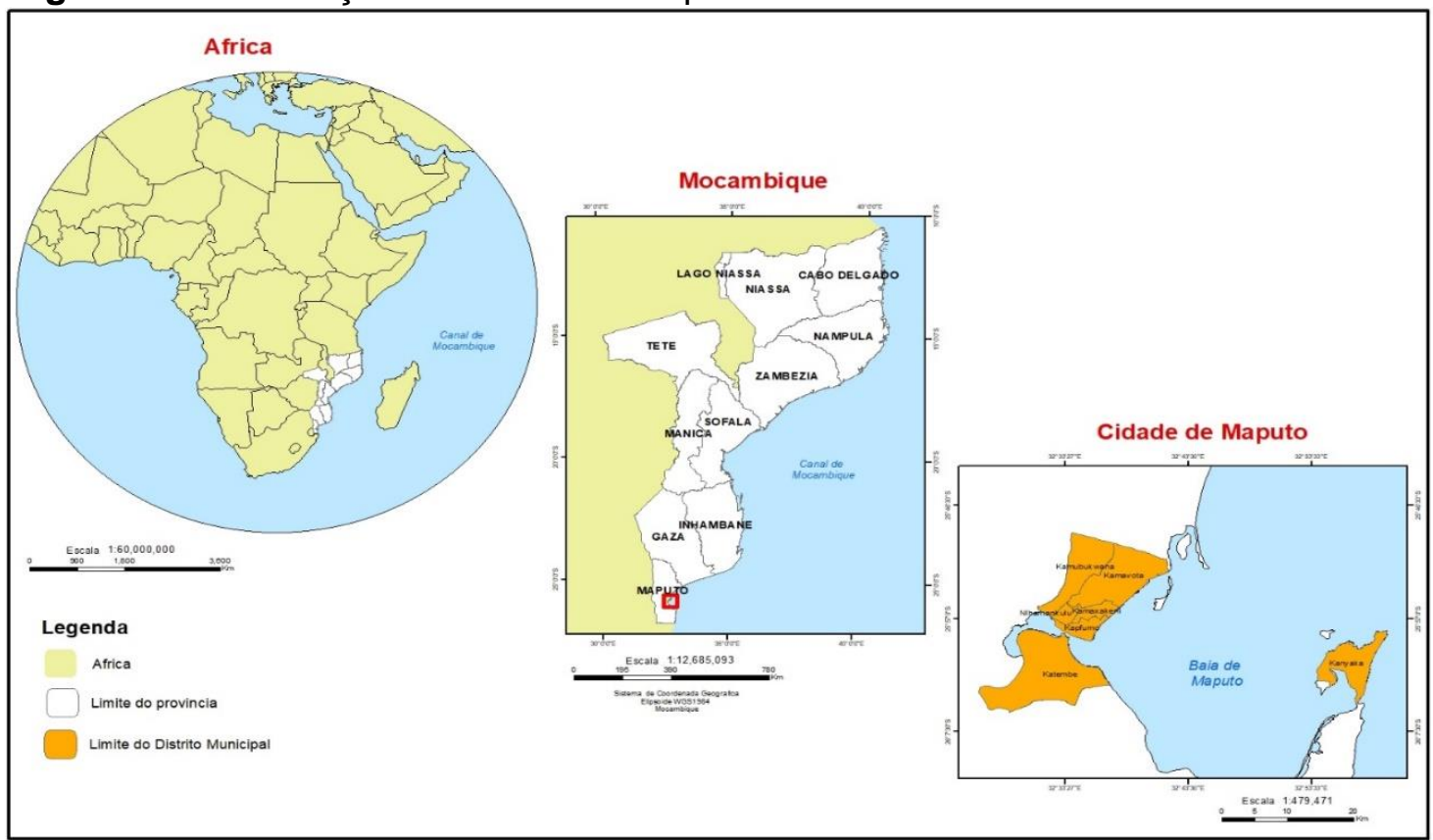

Fonte: Elaborado, a pedido do autor, por Celso Alexandre Vidigal Chivale, FCTA, UP, 2020.

A génese das cidades moçambicanas e, particularmente, da cidade de Maputo, remonta ao período colonial. A dualidade é uma característica que emerge já nesse momento e continua no período pós-independência. Como Araújo (2003, p. 169) referiu:

A cidade colonial, em Moçambique, apresentava uma característica dual muito marcada: por um lado, a chamada "cidade de cimento", branca, de desenvolvimento vertical, planificada, com infraestruturas e serviços; em oposição, a designada "cidade de caniço", negra, suburbana, horizontal, não planificada, de construção espontânea e de material precário (estacas, barro, caniço, etc.), sem infraestruturas e serviços e que se dispunha à volta da "cidade de cimento", cercando-a. 
Através da referida dualidade que apresenta, o autor remete-nos a uma cidade que é cercada por outra, traduzindo assim, mais uma vez, a existência de limites entre as duas. Ou seja, a "cidade de caniço", dominada pela sua "imagem horizontalizada", revela, na justaposição, até onde vai a "cidade de cimento" sem, no entanto, fazê-lo com relação aos seus próprios limites. Ora, no período colonial o subúrbio era o dormitório para a mão-de-obra barata que movia a economia colonial. As autoridades de então tomaram consciência de que o crescimento dos subúrbios constituía desafio à sua "[...] capacidade de absorção e integração destas áreas no tecido urbano de Lourenço Marques" (FORJAZ, 2006, p. 15), tecido este que dava conteúdo ao conceito de cidade. O processo de integração da "cidade horizontalizada" no tecido urbano foi difícil no período colonial e continua a sê-lo no presente.

Sobre os subúrbios estava regrada uma tipologia habitacional com carácter provisório, para que a demolição do edificado, uma vez chegada a tão esperada urbanização, se tornasse uma ação menos onerosa. Por isso, não se tolerava qualquer construção em material durável, o que provocou a proliferação de casas de caniço e as de madeira e zinco. Estava demarcado, já a partir deste período, o espaço da "imagem verticalizada" e, assim, a percepção da cidade branca como sendo cidade, e não propriamente a agregação desta com o subúrbio, a cidade negra, que esperava pela chegada da urbanização (ainda que esta estivesse em processo nesse mesmo espaço). A percepção das diferenças sociais calcava-se assim nessa demarcação entre as duas cidades.

No período pós-independência o processo de urbanização manteve essa consciência se tomarmos em conta que, no essencial, a forte diferenciação espacial resultante da cidade colonial continuou como marca dominante. A "imagem verticalizada”, típica da área central da cidade de Maputo, apresentando-se consolidada com infraestruturas consideradas completas, continuou a corresponder ao espaço onde é mais significativa a concentração de equipamentos e infra-estruturas importantes (menos de $3 \%$ do Território Municipal) para o desenvolvimento da capital de Moçambique (VIANA, 2012). Não temos agora o critério racial representado pela "cidade branca", mas, basicamente, a "imagem verticalizada" que não perdeu o seu estatuto físico, político e económico e a sua influência espacial em várias escalas.

Diferentemente da periferia, que apresenta uma "imagem horizontalizada", a área central da cidade e sua "imagem verticalizada" constituem, por assim dizer, o rosto da cidade e, por essa via, o conteúdo que faz a percepção de cidade. Neste sentido, é perceptível que a periferia, com sua "imagem horizontalizada", continue num lento processo de assimilação da "imagem verticalizada", estruturada, ostentadora de poderio financeiro, que avança no sentido Sul-Norte da cidade numa dinâmica de ocupação de novos espaços, alargando as transformações físicas, sociais e culturais da área central da cidade. A "imagem verticalizada", tanto no período colonial como no pós-independência, sempre correspondeu ao centro 
urbano, o espaço mais caro da cidade, e foi percebida como a "máquina civilizadora" da cidade.

Como se referiram Viana, Sanz e Natálio (2013), a cidade tem sofrido alterações baseadas na informalidade de procedimentos que consubstanciam resposta a constrangimentos cotidianos dos citadinos, ela é “[...] uma cidade 'manufaturada' em tempo real, que expõe modos alternativos de produção de espaço urbano - que vão solvendo e/ou ultrapassando limites. A extensão morfológica acontece entre a ordem e a aparente desordem" (VIANA; SANZ; NATÁLIO, 2013, p. 19), tornando a cidade um espaço de diversidade e diferença como se referiu Hassenpflug (2007).

Estudos desenvolvidos por Araújo (2002) em bairros da cidade de Maputo levaram-no a questionar a linearidade na delimitação clássica de urbano e rural em Moçambique e se isso não se coadunava mais com a questão dos preconceitos do que conceitos, pelo facto de nos limitarmos a aplicá-los "[...] sem deles nos apropriarmos e, mesmo sem mudar de nome, os ajustarmos às realidades concretas e às diferentes formas e percepções de uso e organização do espaço" (ARAÚJO, 2002, p. 5). Deste modo, a imagem do espaço rural, praticamente homogênea, dado o seu carácter horizontal, goza de importância na abordagem sobre o urbano e a cidade numa perspectiva de delimitação espacial. A apropriação do conceito de urbano e cidade chama à percepção a imagem do rural no perímetro da dita "cidade de cimento", o que tem a ver com as migrações e, por essa via, com as medidas tomadas pela edilidade frente à pressão demográfica sobre o espaço. Neste sentido, pelo peso que tiveram, consideramos importantes, na referida apropriação, os seguintes aspectos: i) a coercibilidade na ocupação de Maputo-Cidade induzida pelo fator político-militar e pelos eventos naturais; e, ii) os espaços em torno da cidade capital que, antes considerados rurais, se transformaram administrativamente em urbanos.

\section{A COERCIBILIDADE NA OCUPAÇÃO DE MAPUTO-CIDADE INDUZIDA PELO FATOR POLÍTICO-MILITAR E PELOS EVENTOS NATURAIS}

A coercibilidade, no sentido de que as pessoas se sentiam obrigadas a emigrar, sobretudo do campo para as cidades em busca de segurança, por força da intensidade do conflito político-militar, provocou o crescimento acelerado das cidades. Só entre 1980 e 1997, a população urbana cresceu a uma taxa média que oscilou entre os $6,1 \%$ e os $10,7 \%$, e o crescimento da população rural não ultrapassou os $0,7 \%$, ainda que os níveis de fecundidade fossem elevados como se referiu Feijó (2018). A cidade de Maputo, onde o crescimento urbano foi mais expressivo, viu a sua população duplicar em pouco mais de uma década, ou seja, segundo os dados avançados por Feijó (2018), a cidade passou de 378.348 habitantes, em 1970, para 871.776 , em 1991, altura em que 44,6\% eram originários de fora da cidade e 
maioritariamente do Sul do país, com destaque para a província de Maputo. Um crescimento motivado, sobretudo, pela guerra, como referido por Feijó (2018).

Ora, este movimento de migrações forçadas não deixa de lado os recorrentes eventos naturais como as cheias e secas bem como o impacto das nacionalizações (em 1976), um ano após a independência nacional. As referidas nacionalizações abarcavam a terra e os prédios de rendimento, tanto para habitação como para outros fins como os comerciais, as inúmeras unidades económicas, agrícolas e urbanas, os serviços de educação, a saúde e a advocacia, entre outros e, em paralelo, "[...] as políticas do Governo Moçambicano, nesse período, incentivaram as pessoas a ocuparem as cidades, ficando o custo de manutenção e gestão urbanística à responsabilidade do Estado" (FRANCISCO; PAULO, 2006, p. 24). Desse modo, a chamada "cidade de cimento", deixou de ser "branca", e, por seu turno, a designada "cidade de caniço", que já era "negra", adensou-se e ganhou espaço em extensão. Na primeira, foi ocorrendo a apropriação da cidade colonial em paralelo com a crescente pressão populacional, despoletando o conflito entre a vivência urbana e a vivência rural.

Assim, a brusca sinalização de apropriação da cidade colonial, por novos ocupantes, foi reveladora de que a aquisição e assimilação dos valores urbanos punha à prova a imagem do rural, no sentido do seu desenraizamento. Em paralelo, o tempo dessa assimilação tardava porque o conflito político-militar continuava a impactar social e economicamente a cidade tanto em termos de provimento de serviços urbanos (muitos deles descontinuados), como de adensamento nos vários tipos de habitação. Adiciona-se a este aspecto a crescente deterioração da mobilidade nos prédios, não só por conta, por exemplo, do elevador/ascensor, lembrado em dias de muita necessidade, ligada à saúde, ou mesmo para facilitar o transporte de um bem, entre outros, mas também devido à precariedade das condições ambientais. Esta situação, de um modo geral, verificava-se não só nos prédios como nas ruas e avenidas, entre outros espaços. Vivia-se uma situação política, económica e urbanística resultante do impacto do conflito militar. Neste sentido, Francisco e Paulo (2006, p. 28) referiram que:

[...] no período pós-independência, a situação urbanística e económica precária não tardou a agravar-se. A política populista e ideologizada que passaram a orientar os destinos da economia de Moçambique, conduziu o Estado a assumir o controle dos sectores vitais da economia, ao dispêndio de gastos públicos, a programas assistencialistas e ao empreguismo oficial, sem se preocuparem em fazer a avaliação de custos e benefícios.

O acelerado crescimento populacional, segundo Viana, Sanz e Natálio (2013, p. 23), fez com que a transformação da capital moçambicana ocorresse "[...] de modo auto-organizado, quase fora de controlo político e administrativo. A forma da cidade desdobra-se em fragmentos 'solventes', cujos contornos foram substituídos pela indefinição de limites do espaço urbano [...]". O referido agravamento da situação urbanística pode ter sido geral, no 
entanto, foi muito mais sentido nas áreas em redor do centro urbano da cidade Maputo, pela ideologia política em associação com o tipo de economia vigente nessa altura. A "imagem verticalizada" pode ter transmitido, então, a importância do seu peso social e político. $O$ sentido de pertença a cidade é contrabalançado com a necessidade de subsistência nas economias familiares/domésticas.

A partir das primeiras eleições multipartidárias, em 1994, não tendo sido apropriada a cidade, em termos de vivência urbana, o sentimento de pertença começou a ceder diante dos impactos da introdução da economia de mercado. Ou seja, relegar a cidade para as famílias ou indivíduos de maiores posses financeiras passou a constituir um importante movimento na produção e expansão da cidade em paralelo com o renascimento do setor imobiliário e relação positiva entre a indústria de construção e a necessidade de autoconstrução. Esta processouse no sentido de construção de casa própria ou de elevação dos padrões habitacionais em substituição dos anteriores, bastante precários. Os fundamentos do "socialismo" ou "marxismo moçambicano" perdem espaço em favor de um capitalismo que vai ofuscando paulatinamente a inércia do primeiro. $O$ avanço dos sinais de uma economia urbana a impor regras e padrões consentâneos com a vivência urbana passa a ser extensivo ao espaço que, em termos jurídicos e administrativos, é o território que constitui a cidade de Maputo, com os seus sete distritos urbanos. Mesmo assim, a percepção das diferenças sociais continua a encontrar fundamento na diferenciação espacial, tanto mais que é muito mais visível a preocupação com a "imagem verticalizada", por parte da administração urbana, do que com a "imagem horizontalizada", ainda que as dificuldades financeiras continuem a ser usadas para justificar a pouca oferta de serviços.

Prevalece assim uma distribuição da cidade que não difere da morfologia urbana herdada do período colonial. As relações entre a área central e o seu espaço de influência, num primeiro momento atingindo o suburbano e o periurbano, e, com o tempo, ampliando-se para um nível regional e nacional, contribuíram para a percepção do seu peso na sua zona de influência política, económica e até cultural. Deste modo, a grandiosidade da cidade, percebida não propriamente na extensão que abarca todos os sete distritos urbanos, alguns deles com um carácter marcadamente rural (como KaNyaka e KaTembe), mas por meio da ostentação do poderio financeiro visível através da sua dimensão física representada por monumentos, edifícios, praças, ruas, avenidas etc., continuou no imaginário das pessoas, fazendo o conteúdo de cidade. Assim, assumimos a "grandiosidade da cidade" como a percepção criada através de estímulos exteriores a partir da expressão física da cidade (densidade de edifícios em altura, a própria altura dos mesmos, qualidade e quantidade de ruas e avenidas, etc.), da ostentação do poderio político e financeiro (instituições políticas, concentração de instituições financeiras e nível de fluxo monetário), da aglomeração humana 
(presença de nacionais e estrangeiros), do nível de diferenciação espacial e social (homogeneidade e/ou heterogeneidade), entre outros.

A grandiosidade da cidade, irradiada a partir do centro, e não a sua enormidade comparativamente a outras cidades de Moçambique, criou a percepção de que a mesma é que, de fato, constituía cidade. O entendimento é que o crescimento ou avanço do centro urbano corresponde ao avanço da cidade, o que é observável pela avenida Marginal, pela "Circular de Maputo", pelos bairros (no sentido Sul-Norte) etc.; espaços que constituem o território de Maputo-Cidade, tendo por base a expressão "a cidade um dia vai chegar aqui" dito pelos habitantes das periferias (alguns deles "provenientes" da área central). A evidência é notória na "cedência" dos lotes ou talhões, no espaço da "imagem horizontalizada", que tem sido prática nas últimas décadas, por parte das famílias de menores posses. A maior ostentação de riqueza, maior oferta de oportunidades de emprego, o ordenamento territorial apresentado, a facilidade na mobilidade urbana, a maior concentração de edifícios (em altura) e maior asfaltagem, entre outros aspectos e benefícios, também perfazem os elementos da grandiosidade da cidade, e reforçam a "imagem verticalizada".

Associa-se a este aspecto da percepção da grandiosidade a questão do tratamento diferenciado, por exemplo, nos níveis de acesso ao saneamento, que prevalece, quando se compara o centro e a restante parte da cidade (administrativa). Por exemplo, em MaputoCidade, os níveis de acesso aos serviços de saneamento são diferentes, como notou Feijó (2018). Segundo este autor, 100\% da população do distrito KaMpfumo (largamente a "cidade de cimento", aquela da "imagem verticalizada" por excelência) tem acesso a fossa céptica ou a latrina melhorada, diminuindo essa taxa nas áreas suburbanas, espaço da "imagem horizontalizada", como nos casos dos distritos urbanos KaLhamankulo (78\%) e KaMaxaquene (76\%), bem como nas áreas periurbanas, com os casos dos distritos urbanos KaMavota (76\%), KaMubukwana (75\%) e KaTembe (55\%).

O tratamento diferenciado numa mesma cidade contribui, ou têm contribuído, em certa medida, para reforçar a percepção de condição periférica dos restantes dos distritos urbanos, diante do KaMpfumo. Ao se dispender maior atenção a este distrito, concretamente à área central, em termos de serviços por parte da administração urbana, esvazia-se a percepção do sentido de cidade na perspectiva político-administrativa, fazendo com que os limites entre o distrito em referência e os outros sejam definidos a partir da percepção gerada pela grandiosidade e pelo forte peso da sua centralidade. 


\section{OS ESPAÇOS EM TORNO DA CIDADE CAPITAL QUE, ANTES CONSIDERADOS RURAIS, SE TRANSFORMARAM ADMINISTRATIVAMENTE EM URBANOS}

Historicamente, a cidade de Maputo pode ser dividida em dois grandes momentos do ponto de vista da urbanização. Um primeiro momento, que corresponde ao período colonial, cuja realidade é o surgimento da cidade de Maputo (ex-Lourenço Marques), num processo alógeno, e um segundo momento, o do pós-independência, em que a cidade cresce em extensão como resultado da rápida urbanização acrescida de processos políticoadministrativos.

No primeiro momento a percepção de cidade é condicionada pelo respectivo carácter alógeno. É a cidade implantada segundo o modelo europeu que cresce até sensivelmente ao espaço correspondente ao distrito KaMpfumo (antigo distrito urbano no 1). No segundo, há uma significativa expansão urbana e o território da cidade ganha novos limites legitimados pelo crivo político administrativo. No entanto, o lugar da cidade continua a ser percebido como a área central - espaço verticalizado; assim percepcionada tanto na cidade verticalizada como na horizontalizada.

Durante o conflito político-militar, conhecido como a Guerra dos 16 Anos, pouco depois de meados da década de 1970 até aos princípios da década de 1990, o abastecimento da cidade a partir do campo era praticamente insignificante; tanto mais que, como vimos, os camponeses abandonavam o campo em busca de segurança em cidades, como a de Maputo. Os eventos naturais (severos) também contribuíam nessa movimentação. Praticamente não se produzia para a cidade e as aglomerações valiam-se das importações que o país fazia, sobretudo a partir do dito mundo socialista (Bulgária, Roménia, ex-União Soviética etc.).

Os circuitos comerciais, entre a cidade de Maputo e outras, desenvolviam-se com imensas dificuldades, pois os espaços entre as mesmas constituíam potenciais focos de instabilidade militar. A maior preocupação residia, assim, na intensificação da segurança nas cidades e não nas trocas comerciais. O abandono do campo para a cidade de Maputo fez com que o mesmo se tornasse a representação do atraso económico, social e cultural; um espaço estagnado. A cidade tinha como maior oferta a segurança e alguma crença, difícil de fundamentar, de que a mesma não poderia ser alvo de destruição. Ainda assim, esta suposta "intocabilidade", com o tempo, tornou-se praticamente inquestionável.

Neste sentido, a crise generalizada gerou o efeito de estagnação da cidade de Maputo em termos qualitativos, mas não em termos quantitativos. A economia urbana "implodiu" paralelamente à "explosão" da urbanização. Este aspecto pode ser percebido na reclassificação administrativa referida por Araújo $(2005$, p. 7$)$ do seguinte modo: 


\begin{abstract}
O núcleo mais antigo e mais urbanizado da cidade corresponde ao D.U. 1, exceptuando as localidades urbanas da Catembe e da Inhaca. Em contraste, os D.U. 4 e D.U. 5, em conjunto com aquelas duas localidades, são os que se localizam nas áreas mais periféricas da cidade, sendo resultado do crescimento urbano dos anos pós-independência. Alguns dos bairros destes dois distritos, assim como a Catembe e a Inhaca, eram, até 1986, espaços rurais pertencentes ao distrito de Marracuene e de Matutuíne. A reclassificação administrativa que nesse ano teve lugar, além de separar, administrativamente, as cidades de Maputo e da Matola, absorveu para a área urbana de Maputo, vários espaços povoados daqueles dois distritos, transformando-os, por decreto, em espaços urbanos periféricos, que passaram a funcionar como áreas de expansão da cidade.
\end{abstract}

A reclassificação urbana, agregando por decreto o rural ao urbano, e estendendo o território da cidade de Maputo, implicou ganhos em termos territoriais e de população, e, atendendo à situação político-militar que se vivia, protegeu a própria área central, a já referida "cidade de cimento". Ou seja, houve também um ganho em termos de segurança. Tanto é que pareceu não estar em causa o reforço em recursos humanos para lidar com a nova realidade territorial. Aliás, em termos de recursos humanos continua a se observar uma cobertura muito aquém da necessitada para dar vazão e celeridade às solicitações e exigências dos cidadãos de Maputo-Cidade.

Com a considerada "ruralização da cidade" estenderam-se as relações de solidariedade e proteção social entre os rurais que migravam para a cidade, como notaram Francisco e Paulo (2006), num processo de urbanização de suas vidas, abandonando práticas sem inserção em meio urbano. Na "cidade de cimento", exemplos como a destruição sucessiva do parquet para uso na confecção de alimentos, à imitação do combustível lenhoso; como o executar de danças vigorosas cujo hábito era o de levantar a poeira do chão, mas que ocorriam, por exemplo, em pleno $9^{\circ}$ ou $12^{\circ}$ andares; como o hábito de pilar amendoim ou outro produto num andar elevado de um prédio, entre outros, constituíram parte dessa ruralização e alguma má percepção do sentido das nacionalizações. Encontramos nessas atitudes a percepção de se estar na cidade pelo entendimento de que aquelas práticas não deviam ser desenvolvidas em meio urbano, mas a pressão do conflito político-militar não lhes dava outra escolha. Tanto mais que a periferia, espaço mais consentâneo com essas práticas, desenvolvia sua própria dinâmica em termos de regras e padrões de ocupação e vivência. Os "ruralizadores" encontraram nas "nacionalizações" os ganhos da luta contra a dominação colonial. Por seu turno, a organização espacial da cidade de Maputo e respectiva grandiosidade proporcionavam a percepção sobre o lugar da ruralização e, deste modo, os limites entre o campo e a cidade. A percepção sobre as duas formas de espaço, perfazendo a cidade dual, derivava assim da vivência suburbana e periurbana a partir de filtros culturais muito dominados pela subjugação. 


\section{RESULTADOS E DISCUSSÃO DOS RESULTADOS DA PESQUISA DE CAMPO}

Duas questões conduziram a pesquisa: a primeira teve em conta o entendimento dos inquiridos sobre os limites geográficos da cidade de Maputo e a segunda procurou a percepção dos mesmos sobre o que era, para eles, a cidade de Maputo. Com base em um tamanho da população de 90 indivíduos/estudantes, um grau de confiança de $85 \%$ e uma margem de erro de $10 \%$ foi obtido como tamanho da amostra 34 estudantes (SURVEYMONKEY, 2018). Todos eles no ensino superior, curso de geografia, inquiridos na cidade de Maputo, entre jovens (maioritariamente) e adultos, sendo 20 mulheres e 14 homens. A administração do inquérito teve por base o fator surpresa, de modo a evitar a troca de impressões, para que as respostas transmitissem uma percepção não contaminada. À altura do inquérito (agosto de 2018) os inquiridos residiam nos vários bairros de Maputo-Cidade bem como de Matola e Boane (Tabela 1).

Tabela 1 - Inquiridos por residência Inquiridos por residência

\begin{tabular}{|c|c|c|c|}
\hline Cidade & $\begin{array}{l}\text { Residência dos } \\
\text { inquiridos }\end{array}$ & Sub-total & $\%$ \\
\hline \multirow{7}{*}{ Maputo } & Ka Mpfumo & 0 & 0 \\
\hline & Ka Nlhamankulo & 6 & 18 \\
\hline & Ka Maxaquene & 1 & 3 \\
\hline & Ka Mavota & 2 & 6 \\
\hline & Ka Mubukwane & 8 & 24 \\
\hline & Ka Tembe & 0 & 0 \\
\hline & Ka Nyaka & 0 & 0 \\
\hline \multirow{3}{*}{ Matola } & Infulene & 7 & 21 \\
\hline & Machava & 4 & 12 \\
\hline & Matola sede & 4 & 12 \\
\hline \multirow[t]{2}{*}{ Boane } & Matola Rio & 1 & 3 \\
\hline & Boane sede & 1 & 3 \\
\hline TOTAL & & 34 & 100 \\
\hline
\end{tabular}

Fonte: o próprio autor.

Sobre o entendimento dos inquiridos com relação aos limites de Maputo-Cidade dois grupos se destacaram: um primeiro, maioritário, cuja percepção não coincide com os limites administrativos (oficiais) e um segundo, de pouca expressão, que se aproximou aos referidos limites. Ou seja, com relação à percepção sobre os limites geográficos da cidade de Maputo, 
$94 \%$ contra $6 \%$ foi ao encontro da "indefinição de limites" respondendo, por exemplo, o seguinte:

- A cidade de Maputo vai "da Portagem até à zona presidencial”; “... da Sommerchield até à Drenagem"; "[...] da Baixa da cidade até à Portagem"; "Parte de Marracuene até Boane"; "É da Manhiça até Matola"; "Faz limites com KaTembe"; "No Norte encontramos o Distrito urbano Ka Mubukwane e no Sul Ka Tembe"; "É de Marracuene até ao rio Mulauze"; "Corresponde à própria Baixa, Museu e Aeroporto" etc. Diferentemente destas respostas, encontramos: "Para mim a cidade a Norte é limitada pelo distrito de Marracuene; a Sul, pela Baía de Maputo; a Oeste faz fronteira com a Cidade da Matola; e a Este (não respondeu)"; e a única resposta que coincidiu com limites administrativos (oficiais) foi a seguinte: "No meu entendimento a cidade de Maputo é limitada a Norte pelo distrito de Marracuene; a Sul pelo distrito de Matutuine; a Oeste pelo Município da Matola e a Este pela Baía de Maputo".

O primeiro grupo de respostas teve como foco a apreensão e percepção do espaço como resultado de fortes relações espaciais e económicas existentes entre a cidade de Maputo, a de Matola e a vila de Marracuene. Traduziram, em parte, a percepção do espaço de influência da cidade, partindo da sua área central. Notar que, em 1980, as referidas relações influenciaram a integração de Matola (cidade dormitório e grande parque industrial) a Maputo (com a sua atividade ferro-portuária e concentração dos serviços). A partir daí a referência à expressão oficial "Grande Maputo" começou a ganhar relevância. Oito anos depois a cidade da Matola foi administrativamente desanexada à cidade de Maputo tendo ganho um novo estatuto já como capital da Província de Maputo. Entretanto, a mobilidade laboral no sentido Matola-Maputo e vice-versa, as relações económicas, culturais e familiares, permaneceram como se a medida administrativa não passasse disso, tendo efeitos apenas no campo político-administrativo.

A “indefinição de limites do espaço urbano", já referida por Viana, Sanz e Natálio (2013), pode ter contribuído para a heterogeneidade na percepção dos limites geográficos de MaputoCidade. Reforçam este aspecto as diferentes legibilidades entre os espaços, tendo como referência a "cidade de cimento". A referida "indefinição" constitui o conjunto de limites percepcionados. Estes podem ser definidos como aqueles percebidos pelo indivíduo ou conjunto de indivíduos, sem a influência do carácter político-administrativo, ainda que haja consciência sobre o mesmo, e que os permitem interagir socialmente no quadro das relações espaciais que se estabelecem entre os vários lugares.

Sobre o "que era, para eles, a cidade de Maputo", segunda questão, as respostas foram variadas, em sua maioria, sem, no entanto, prescindir da "imagem verticalizada" do ponto de vista de infraestrutura e de importância política e económica. Desse modo, as respostas traduziram a percepção da legibilidade dos lugares, a sua materialidade e singularidade e/ou importância. As mesmas incidiram, por exemplo, sobre a existência de escolas, hospitais e 
transportes públicos; empresas, fábricas e infraestruturas administrativas; espaços de lazer e de existência de instituições privadas; edifícios, museus e ministérios; consideraram MaputoCidade como uma "área muito povoada por pessoas de outras províncias"; "É a cidade das oportunidades e com boa mobilidade"; "É a zona que não é agrícola"; "É a área de maior desenvolvimento económico e com maior número de prédios"; "É onde temos avenidas bem estruturadas"; "É onde se encontra o Governo central e os ministérios"; e, relativamente num sentido mais elaborado "É aquela devidamente ordenada e que apresenta infraestruturas convencionais e com concentração económica e expande-se até aos locais vizinhos"; "É o local de aglomeração de vários serviços, onde encontramos avenidas, ruas largas, com concentração de diversos serviços, é um local bem estruturado, com infraestruturas, centros comerciais, bancos, e é onde também as pessoas têm esperança de emprego e negócios".

A percepção dos inquiridos revelou que a cidade não é, para eles, um elemento estranho. Vivem nela através das relações que se estabelecem nos níveis intra-urbano e interurbano. O ritmo em que as dinâmicas urbanas ocorrem continua a marcar a diferença entre a presença da "imagem verticalizada" e a "imagem horizontalizada". As diversas percepções sobre os limites da cidade, na esteira dos limites percepcionados, constituíram uma leitura do ambiente e do modo como os indivíduos se inserem no espaço em que se encontram, podendo ser vistas como não definitivas, uma vez que percepções evoluem no tempo e no espaço.

A cidade de Maputo deriva de um processo histórico com um carácter alógeno, tendo sido marcada, no período pós-independência, por uma considerável expansão da urbanização. As percepções subjazem esta perspectiva histórica. Daí que o avanço da cidade, como um todo, continue a manter o seu caráter "dual". A expansão da "imagem verticalizada" não se circunscreve ao centro urbano, e avança sobre os espaços suburbanos e periurbanos. Em extensão, a "imagem horizontalizada", porque essencialmente visível na sua homogeneidade, confunde os limites (entre a ordem e a desordem) não se conformando com o caráter administrativo.

Nesse avanço, a "imagem verticalizada" vai pontilhando não só esses espaços da "imagem horizontalizada" como também vai imprimindo a necessidade de se adequar o conceito de "centro" à realidade da cidade de Maputo. Entretanto, o próprio "centro" continua a ter ganhos significativos em termos de construções em altura, por meio da ocupação paulatina dos espaços baldios e outros, fortalecendo a sua centralidade. Deste modo, diversifica os limites percepcionados da cidade de Maputo e, em interface, cria espaço para que a "imagem verticalizada" seja assumida como sinónimo de cidade, dando conteúdo à ideia de cidade. 


\section{CONSIDERAÇÕES FINAIS}

A técnica de análise de textos levou-nos a concluir que os limites da cidade de Maputo estabelecidos administrativamente, agregando, por um lado, a "cidade de cimento" ou área central que aqui correspondeu à "imagem verticalizada" e, por outro, a área correspondente à "cidade de caniço" ou periferia, que pela sua homogeneidade foi aqui tratada como "imagem horizontalizada", não foram acompanhados por mudanças qualitativas que expandissem o conceito de "cidade" tendo por referência a área central. Manteve-se a diferenciação espacial de génese alógena, mais tarde reforçada pela rápida urbanização. Tanto no período colonial como após a independência de Moçambique a percepção do espaço encontrou na dualidade os atributos de cidade fundados na "imagem verticalizada" e numa perspectiva que traduz a modernidade. A "imagem horizontalizada", por seu turno, passou a gozar administrativamente do estatuto de cidade pela sua proximidade relativamente ao centro, permanecendo, assim, como um conjunto reivindicador de melhorias na qualidade espacial urbana. É um espaço que perfaz a cidade, mas é percepcionado tendo em conta a "imagem verticalizada", aquela de maior legibilidade.

A pesquisa de campo permitiu aferir a existência de grande diversidade na identificação dos limites da cidade em causa. No entanto, houve convergência geral com relação ao conteúdo de cidade, coincidindo este com a "imagem verticalizada" e não propriamente com os limites administrativos que incluem a "imagem horizontalizada".

A percepção visual, distinguindo diferentes espaços por meio de suas particularidades, dentro do raio administrativamente considerado como sendo Maputo-Cidade, ofereceu diversos entendimentos sobre a legibilidade dos limites da cidade. O olhar foi fortalecido pelo "centro" como espaço difusor da ordem económica, política e social. A "imagem verticalizada", protuberante sobre a "imagem horizontalizada", condicionou as percepções relativas ao conteúdo de cidade. Assim, a protuberância da "imagem verticalizada" gerou diversas leituras ditadas pela legibilidade dos espaços, criando uma diversidade de limites percepcionados.

\section{REFERÊNCIAS}

ARAÚJO, J. A. Sobre a cidade e o urbano em Henri Léfèbvre. GEOUSP: espaço e tempo (Online), São Paulo, n. 31, p. 133-142, ago. 2012. Disponível em: http://www.revistas.usp.br/geousp/article/view/74258/77901. Acesso em: 31 jul. 2018.

ARAÚJO, M. Os espaços urbanos em Moçambique. GEOUSP: espaço e tempo (Online), São Paulo, n. 14, p. 165 -182, 2003. Disponível em:

http://www.revistas.usp.br/geousp/article/view/123846. Acesso em: 17 ago. 2018.

ARAÚJO, M. População das cidades de Maputo e Matola: espaços urbanos multifacetados. Maputo: Centro de Estudos da População (CEP): UEM, 2005.

ARAÚJO, M. Ruralidades-urbanidades em Moçambique. Conceitos ou preconceitos?

Revista da Faculdade de Letras: geografia. Porto, v. 18, p. 5-11, 2002. 
FEIJÓ, J. Investimentos económicos, assimetrias socio-espaciais e movimentos migratórios. In: FEIJÓ, J.; RAIMUNDO, I. M. (coord.). Movimentos migratórios para áreas de concentração de grandes projectos. Maputo: PubliFix Edições, 2018. p. 17-61.

FORJAZ, J. (coord.). Moçambique, melhoramento dos assentamentos informais, análise da situação \& proposta de estratégias de intervenção. Maputo: Direcção Nacional de Planeamento e Ordenamento Territorial (DINAPOT): Ministério para a Coordenação da Acção Ambiental (MICOA), 2006.

FRANCISCO, A. A. S.; PAULO, M. Impacto da economia informal na protecção social, pobreza e exclusão: a dimensão oculta da informalidade em Moçambique. Maputo: Cruzeiro Sul e Centro de Estudos Africanos, 2006.

GAVA, A. Sobre a definição de observação como percepção verdadeira justificada. Scientiae Zudia, São Paulo, v. 13, n. 1, p. 123-41, 2015.

HASSENPFLUG, D. Sobre centralidade urbana. Arquitextos, São Paulo, ano 8, n. 85, jun. 2007. Disponível em: https://www.vitruvius.com.br/revistas/read/arquitextos/08.085/235. Acesso em: 20 jul. 2018.

KANASHIRO, M. A cidade e os sentidos: sentir a cidade. Desenvolvimento e Meio Ambiente, Curitiba, n. 7, p. 155-160, jan./jun. 2003.

LENCIONE, S. Observações sobre o conceito de cidade e urbano. GEOUSP: espaço e tempo (Online), São Paulo, n. 24, p. 109-123, abr. 2008. Disponível em: http://www.revistas.usp.br/geousp/article/view/74098/77740. Acesso em: 20 jul. 2018.

MALANSKI, L. M. Geografia humanista: percepção e representação espacial. Revista Geográfica de América Central, Heredia, n. 52, p. 29-50, 2014. Disponível em: http://www.redalyc.org/articulo.oa?id=451744543002. Acesso em: 15 jul. 2018.

MUÑOZ, J. L. V. Análisis de textos en geografía de la percepción: estado de la cuestión y bases conceptuales. Baetica: estudios de arte, geografía e historia, Teatinos, v. 32, p. 127146, 2010.

SANTOS, M. A Cidade como centro de região: definições e métodos de avaliação da centralidade. Salvador: Livraria Progresso Editora, 1959.

SCOCUGLIA, J. B. C.; CHAVES, C.; LINS, J. Percepção e memória da cidade: o ponto de cem réis. Arquitextos, São Paulo, ano 6, n. 68, jan. 2006. Disponível em:

http://www.vitruvius.com.br/revistas/read/arquitextos/06.068/393. Acesso em: 30 jul. 2018.

SMITH, P. J. A Percepção como uma relação: uma análise do conceito comum de percepção. Analytica, Rio de Janeiro, v. 18, n. 1, p. 109-132, 2014.

SURVEYMONKEY. Calculadora de tamanho de amostra. Disponível em: https://pt.surveymonkey.com/mp/sample-size-calculator/. Acesso em: 20 jul. 2018.

VASCONCELOS, P. A. A cidade, o urbano, o lugar. GEOUSP: espaço e tempo (Online), São Paulo, n. 6, p. 11 -15, ago. 2006. Disponível em:

http://www.revistas.usp.br/geousp/article/view/123359/119695. Acesso em: 31 jul. 2018.

VIANA, D. L. A urbanização extensiva [in]formal em Maputo a partir da reticula colonial. In: CONGRESSO INTERNACIONAL SABER TROPICAL EM MOÇAMBIQUE: HISTÓRIA, MEMÓRIA E CIÊNCIA, 2012, Lisboa. Atas [...]. Lisboa: Instituto de Investigação Científica Tropical (IICT), 2012. p. 1-21.

VIANA, D. L.; SANZ, J.; NATÁLIO, A. Aprendendo com a forma urbana de Maputo (in)formal. Revista de Morfologia Urbana, Porto Alegre, v. 1, p. 17-30, 2013.

Recebido: novembro de 2019. Aceito: fevereiro de 2020. 